Pasados suspendidos. Estrategias represivas y tecnologías biopolíticas sobre las disidencias sexo-genéricas durante la dictadura de Augusto Pinochet en Chile Fernanda Carvajal

páginas / año 11 - n 27 Septiembre-Diciembre / ISSN 1851-992X/ 2019

http://revistapaginas.unr.edu.ar/index.php/RevPaginas

\title{
Pasados suspendidos. Estrategias represivas y tecnologías biopolíticas sobre las disidencias sexo- genéricas durante la dictadura de Augusto Pinochet en Chile
}

\author{
Suspended Pasts. Strategies of repression and biopolitical \\ technologies on sexual and gender dissidence during Augusto \\ Pinochet dictatorship in Chile
}

\author{
Fernanda Carvajal \\ Universidad de Buenos Aires, \\ Instituto de Investigaciones Gino Germani, \\ Consejo Nacional de Investigaciones Científicas y Técnicas (Argentina)
}

\begin{abstract}
Resumen
El presente artículo se propone comprender de qué modo el foco sobre las formas de represión y control biopolítico de las disidencias sexogenéricas entre los años sesenta y ochenta en Chile, permiten interrogar las formas de periodización que han organizado los relatos de la historia reciente bajo la distinción dictadura/posdictadura. Comienzo analizando cómo se ha abordado hasta ahora la pregunta sobre las políticas represivas dirigidas a la población LGBT durante la dictadura, en torno a dos grandes ejes: aquella que denuncia la violencia militar hacia a la población LGBT, y postula la necesidad de que se reconozcan como crímenes del Estado dictatorial y aquella que postula que la población LGBT se mantuvo al margen creando formas paralelas de libertad sexual y de circulación habilitada por el mercado. En el segundo apartado, propongo que durante la dictadura es posible identificar otras formas de regulación sexo-genérica en relación a la discreta vía médico-legal de "cambio de sexo" que permitió el acceso de mujeres transexuales a cirugías de modificación genital en hospitales públicos y clínicas privadas. En el último apartado me pregunto cómo se articulan las formas históricas de criminalización de la homosexualidad y el travestismo con las tecnologías biopolíticas que permitieron el desbloqueo de la transexualidad como diagnóstico durante el período dictatorial.
\end{abstract}

Palabras Clave

estrategias represivas; disidencias sexo-genéricas; dictadura; biopolítica; "cambio de sexo".

\section{Abstract}

Esta obra está sujeta a la Licencia Reconocimiento-NoComercial-CompartirIgual 4.0 Internacional de Creative Commons. http://creativecommons.org/licenses/by-nc-sa/4.0/

(cc) BY-NC-SA 


\section{Fernanda Carvajal}

This article aims to understand how the focus on the forms of repression and biopolitical control of sexual and gender dissidence in the seventies and eighties in Chile, allow us to interrogate the forms of periodization that have organized recent history under the distinction between dictatorship / post-dictatorship. I start by analyzing two ways in which repression against the LGBT population during the dictatorship has been addressed: one that demands that the crimes of the security forces on the LGBT population should be recognized as crimes of the dictatorial state and another, which postulates that the LGBT population remained on the sidelines by creating parallel forms of sexual freedom and circulation, enabled by the market. In the second section, I propose that during the dictatorship it is possible to find other forms of sexual and gender regulation in relation to the discrete medical-legal procedures of "sex change" that allowed the access of transsexual women to genital reassignment surgery in public hospitals and private clinics. In the last section, I analyze how the historical forms of criminalization of homosexuality and transvestism were articulated with biopolitical technologies that allowed the emergence of transsexuality as a diagnosis during the dictatorial period.

\section{Keywords}

Strategies of repression; biopolitical technologies; sexual and gender dissidence; dictatorship; "sex change".

\section{Introducción}

El presente artículo aborda algunas de las formas de represión y control biopolítico de las disidencias sexo-genéricas que marcaron el período que va entre los años sesenta y ochenta en Chile, para interrogar las periodizaciones que han organizado los relatos de la historia reciente bajo la distinción dictadura/posdictadura. Más específicamente, propongo analizar continuidades y rupturas que trajo consigo el desbloqueo de la transexualidad como diagnóstico en las formas de regulación sexogenérica en el periodo señalado. Planteo que la patologización de la transexualidad se articuló y convivió con la persistencia de la criminalización, por parte del Estado, de homosexuales visibles, travestis y personas trans ${ }^{1}$. Considero que esas formas de criminalización conjugan prácticas de excepción y dinámicas burocráticas regulares que estaban vigentes en el periodo pre-dictatorial, y a la vez, interrogo cómo una serie de prácticas de sexualidad pública plantean nociones extrañas del tiempo ejercen presión sobre la organización del conocimiento

\footnotetext{
${ }^{1}$ A lo largo del artículo opté por el uso alternado de terminología utilizada en los documentos de época analizados, como "cambio de sexo", "transexualidad", "homosexualidad" (que tienen significados objetivantes o patologizantes en diferentes contextos y períodos de tiempo) y terminología contemporánea como "trans"- un término abarcativo que hace referencia a transexales, transgéneros y travestis - "disidencias sexo-genéricas" -que ha sido propuesta desde el activismo para evitar los términos patologizantes o esencializantes- y "cirugías de modificación genital"-que resulta más precisa y evita otras formulaciones que tienden a reproducir la temporalidad del antes y el después de una identidad- en tanto categorías no patologizantes. Esta decisión busca tensionar la distancia entre la historicidad de terminologías usadas en el pasado y aquellas que configuran nuestro momento presente, así como mostrar que la elaboración de categorías y el establecimiento de las diferencias es un proceso inacabado, inestable, que nos confronta a la necesidad permanente de ajuste. Quisiera remarcar también, la renuncia de cualquier tipo de esencialización de las categorías utilizadas, así como también la precaución de evitar elevar cualquiera de las prácticas o subjetividades abordadas como emblema de subversión, transformación o misión histórica.
} 


\section{Pasados suspendidos. Estrategias represivas y tecnologías biopolíticas sobre las disidencias sexo-genéricas durante la dictadura de Augusto Pinochet en Chile}

histórico.

Para abordar estas hipótesis y preguntas, analizo una serie de notas de prensa que dejan huella de la criminalización de la sexualidad y el género disconforme en el espacio público durante dictadura. Los diarios consultados fueron diarios sensacionalistas dirigidos a un público popular: La Tercera de la Hora y Las últimas Noticias (Santiago), La Estrella de Valparaíso y La Estrella del Norte (Antofagasta). Estos diarios pertenecían al grupo COPESA y a la cadena de Agustín Edwards, conglomerados mediáticos que tuvieron participación en la gestación del Golpe Militar y apoyaron a la dictadura (Baltra, 2012). Quisiera señalar que me encontré con las notas de prensa sobre el control de la sexualidad en el espacio público durante el trabajo de archivo de mi investigación doctoral, aunque no eran el foco de mi búsqueda, que estaba dirigida a las noticias sobre las primeras cirugías de "cambio de sexo" en diarios de Santiago y Valparaíso entre los años 1974 y 19772. Sin embargo, la recurrencia de aquellas notas fue configurando una serie que me permitió verificar materialmente en las páginas del mismo diario, que estaban teniendo lugar cirugías de modificación genital en mujeres trans, mientras simultáneamente se aplicaban tecnologías de control del espacio público sobre homosexuales feminizados visibles, locas y travestis. Lo que era menos evidente, eran los actos de sexualidad pública que esas breves notas registraban. Me parece importante mencionar este encuentro "azaroso" con los documentos de prensa analizados, para señalar también que trabajar sobre la historia de las disidencias sexo-genéricas implica confrontarse con archivos irregulares e incompletos, que dificultan el encuentro con información "sustantiva" o "sistemática" sobre una problemática que, hasta ahora, ha sido poco abordada por la investigación académica. En este sentido quisiera remarcar el carácter exploratorio de este trabajo y espero las hipótesis y preguntas que aquí planteo lejos de cerrar, puedan abrir una discusión.

La serie relevada está conformado por notas breves, fieles a los códigos sensacionalistas, que permiten que vidas anónimas accedan al discurso cuando el crimen o la aventura las deja marcadas por un toque de imposibilidad que les permite dejar huella y convertirse así en algo decible (Foucault 2006). La prensa sensacionalista transmuta lo cotidiano en sensacional y convierte las vidas anónimas de aquellos que no entran en la categoría de ciudadanía en mercancías noticiosas, productivizando una inflación informativa que produce golpes de efecto breves cuya fuerza se acaba casi al instante. Considero, con Snorton (2017), que como noticias estas historias están sesgadas y son parciales, dan cuenta de estructuras de pensamiento de la época que hicieron de ellas figuras valiosas por su excentricidad, a la vez que muchas veces eran consideradas como chistes, indicando

\footnotetext{
${ }^{2}$ Durante estos años, la prensa sensacionalista publica una serie significativa de notas con historias de personas transexuales que se sometieron a cirugías de cambio de sexo. En el período que va desde 1974 a 1977 pude recopilar 65 notas sobre transexualidad y "cambio de sexo" en diferentes diarios de tres ciudades -Santiago, Valparaíso y Antofagasta y 32 notas de personas detenidas por el artículo 373 por su condición sexo-génerica.
} 


\section{Fernanda Carvajal}

así su supuesta condición desechable. La investigadora colombiana María del Pilar Betancurt (2005), señala que una de las características de la prensa sensacionalista es su temporalidad, que se jugaría entre la velocidad de lo insólito y un tiempo que parece inmutable: son historias que podrían ser contadas en cualquier época. Desde mi perspectiva, son historias que podrían ser contadas en cualquier época y a la vez no. Pues, junto con el lenguaje sesgado, espectacularizante e injurioso (raros, depravados, drogadictos, amorales), estas breves notas nos entregan datos que permiten verificar algunas de las tecnologías de represión que desde cierto amparo legal se aplicaban sobre homosexuales visibles, locas y travestis de la época (y que eran aplicadas también a las mujeres cis que ejercían el trabajo sexual).

Estas formas de violencia pueden vincularse con lo que Snorton, pensando en las vidas trans negras, ha llamado las formas de "muerte lenta" (Snorton, 2019, p.11) que han transcurrido históricamente al interior de instituciones como hospitales, centros de salud mental, cárceles y comisarías, cuya ubicación es medular dentro de los órdenes biopolíticos y necropolíticos actuales. Órdenes que requieren de una forma "anti-trans" de organizar el tiempo, perpetuando una violencia intolerable pero cotidiana. Formas continuas de vulneración, precarización e incluso de muerte, a las que están expuestas las disidencias sexo-genéricas, como formas de violencia persistente que permiten interrogar si, antes que una excepción, el estado de emergencia no ha devenido ya la regla.

Junto con constatar esta forma continua de la violencia, a lo largo de este artículo planteo que estos documentos dejan huella de pasados suspendidos, es decir, permiten cuestionar la idea historicista del tiempo como un todo progresivo, debido a que perturban la temporalidad de progreso, superación y modernización que el espíritu fundacional de la dictadura buscó instalar como norma histórica (Thayer, 2004). Con la figura de pasados suspendidos, me refiero a relatos e imágenes que tienen la capacidad de suspender el tiempo, en el sentido de detenerlo, como sucede en la interrupción de una colisión entre cosas. 0 bien que tienen la facultad de diferirlo, como hacen en la escritura los puntos suspensivos. Son huellas de vidas que presentan un exceso o un descalce que perturba la linealidad de las narrativas políticas, médicas y legales sobre las disidencias sexo-genéricas, e incluso de la temporalidad progresiva en sí misma, refractando las formas crono-normativas de comprender la gestión biopolítica / necropolítica de los cuerpos. Pero también me interesa cómo esta operación temporal es ineludiblemente espacial, pues lo que queda suspendido, colgado, queda también suelto, lanzado no solo fuera del tiempo sino también del lugar normativo.

\section{Abordajes sobre las disidencias sexo-genéricas en dictadura}

El Informe sobre Chile escrito por Néstor Perlongher (2006 [1980]) luego de un breve viaje a Santiago y Valparaíso en el año 1980, plantea muy tempranamente que las vidas de homosexuales, locas y travestis fue tocada por el poder dictatorial con la violencia inicial de las políticas de aniquilación, para luego verse envueltas en los 


\section{Pasados suspendidos. Estrategias represivas y tecnologías biopolíticas sobre las disidencias sexo-genéricas durante la dictadura de Augusto Pinochet en Chile}

roces más permisivos de una marginalidad urbana "agazapada en las penumbras" (p. 89) -en burdeles, boites, barrios chinos, a los que a fines de los años setenta se sumaría un incipiente mercado gay. Perlongher contrastaba así el "escenario infernal" de los primeros años de la dictadura chilena, con la idea del "paraíso provinciano" (p. 87) que podía surgir cuando el infierno retrocedía o en aquellas zonas donde entraba en latencia. Esta primera lectura, parece haber marcado los abordajes posteriores de la pregunta acerca de si la dictadura chilena, que se extendió entre 1973 y 1990, tuvo o no una política específica y sistemática dirigida a la población $\mathrm{LGBT}^{3}$ por su condición de tal. En efecto, los autores que se han aproximado a este período han fluctuado entre establecer una genealogía política común con las víctimas del Terrorismo de Estado, reclamando que se reconozcan las violencias contra las personas LGBT como crímenes políticos de lesa humanidad (Garrido, 2016; Rivera, 2009; Robles, 2009), y aquellos discursos que enfatizan más bien el descompromiso de una comunidad gay que se hizo lugar a partir de un incipiente nicho de mercado (Contardo, 2011; Salas, 1989). La dualidad así presentada, resulta acorde a una dictadura donde las políticas represivas fueron simultáneas y no posteriores a la implementación de un modo de gobierno neoliberal.

Hasta el momento en que se escribe este artículo, no hay registros historiográficos que permitan afirmar que durante la dictadura chilena haya habido una política represiva sistemática ideada por el régimen militar que tuviera como objetivo la persecución sobre la población LGBT por su condición de tal, como sí ocurrió, por ejemplo, en relación con la homosexualidad masculina durante la dictadura de Stroessner en Paraguay4. Solo hay testimonios no oficiales, fragmentarios y dispersos, que permiten recoger algunos episodios precariamente documentados de la violencia militar contra la población LGBT. En 1974, el Frente de Liberación Homosexual argentino publicó, en $\mathrm{N}^{\circ} 2$ de la revista Somos (Frente de Liberación Homosexual, 1974) la historia de la Lola Puñales, una travesti uruguaya violada, castrada y acribillada por los militares chilenos durante las masacres y fusilamientos que siguieron al 11 de septiembre de 1973. El libro La Manzana de Adán de la fotógrafa Paz Errázuriz y la periodista Claudia Donoso (1990), que reúne voces e imágenes de travestis recogidas entre 1984 y 1988, conisgna la detención de un grupo de homosexuales y travestis en un barco varado en Valparaíso y varias detenciones ilegales de travestis en prostíbulos por parte de militares. Pedro Lemebel (1993) escribió sobre hallazgo de dos cuerpos masculinos "vestidos de

\footnotetext{
${ }^{3}$ La sigla refiere a lesbianas, gays, transexuales, transgéneros, trans y bisexuales.

${ }^{4}$ Como explica Rocco Carbone: "En setiembre de 1959, Bernardo Aranda, un locutor de la Radio Comuneros fue quemado en el departamento donde residía. Con motivo de ese asesinato el stronato desató una razzia y apresó a 108 presuntos homosexuales para esclarecer el motivo de esa muerte, presentada como un hecho relacionado con la vida sexual de la víctima. A partir de ese momento se acuña el sintagma 108 como marca despectiva para indicar a todo homosexual y el sistema sexo/género irrumpe de manera evidente como parte de los cálculos del poder, del cálculo del gobierno. Ese número, que integra el léxico stronista, sigue teniendo plena vigencia en el Paraguay de hoy" (Carbone y Soto 2015, p.187).
} 


\section{Fernanda Carvajal}

mujer" encontrados en las fosas de Pisagua en el norte del país. También el libro Bandera Hueca de Víctor Hugo Robles (2009) recoge el testimonio de La Doctora, una travesti que ejercía el trabajo sexual en la calle San Camilo en Santiago, que relata el asesinato de dos travestis en los días posteriores al golpe de Estado del 11 de septiembre. Y más recientemente Garrido (2016) ha recogió testimonios sobre la violencia policial y civil dirigida a mujeres trans, homosexuales y lesbianas.

Simultáneamente, durante los primeros años de la dictadura, comenzó a crearse en Santiago un incipiente mercado nocturno gay. Mientras la Quinta Cuatro ${ }^{5}$ y la discoteca Quásar (1980) reunían un público homosexual popular, el Bar Burbuja (1976) y la discoteca Fausto (1979) ubicadas en barrios acomodados, estaban dirigidas a un público homosexual de clase media-alta. Como apunte Gonzalo Salazar en su investigación sobre las prácticas de homoerotismo durante las décadas previas al Golpe de Estado: "la dictadura cívico-militar (...) vio emerger un mundo homoerótico ligado a las discoteques, a fines de los setenta, y que sólo a comienzos de los noventa comenzó a emerger lentamente hacia lo público. Entonces, para el sentido común es como si el homoerotismo no hubiera existido antes de esta última década." (Salazar, 2015, p. 9)

Un aspecto importante a señalar es que en Chile no hubo movimientos LGBT organizados públicamente previos a la expansión del VIH-Sida. Uno de los antecedentes de la politización de las disidencias sexo-genéricas durante el gobierno de la Unidad Popular, fue la concentración de travestis y homosexuales que se dedicaban al trabajo sexual que tuvo lugar en la Plaza de Armas en abril de 1973. Algunos documentos permiten pensar que una parte de ese grupo creó el Movimiento de Liberación por el Tercer Sexo. Así lo sugiere una carta publicada el 13 de octubre de 1976 en el diario Las Ultimas Noticias. Sin embargo, hasta ahora no hay más antecedentes de que el grupo haya realizado acciones públicas o haya tenido continuidad (Contardo, 2011; Robles, 2009). Durante la dictadura surgieron algunos colectivos que funcionaban de manera privada, como el grupo Integración, de tendencia católica, conformado por varones gay en 1978 y el colectivo lésbicofeminista Ayuquelén en 1984. Ambos mantuvieron el anonimato de sus integrantes. Luego de que se hiciera público el primer caso de VIH-Sida ${ }^{6}$, se constituyeron a partir de 1987, las primeras agrupaciones conformadas por homosexuales visibles: la Corporación Chilena Contra el Sida de Santiago y el Centro de Educación y Prevención en Salud Social y Sida de la ciudad de Concepción. Ese mismo año el colectivo de agitación cultural Yeguas del Apocalipsis inició sus acciones en el campo cultural. Fue recién en 1991 que se conformaron las primeras agrupaciones

\footnotetext{
${ }^{5}$ La Quinta Cuatro era una quinta de recreo ubicada en calle Zapadores en el barrio Recoleta, donde "acudían a divertirse matrimonios con hijos hombres heterosexuales solos, travestis, proxenetas y hombres gay de sectores populares y algunos de sectores más acomodados" (Contardo, 2011, p. 332). ${ }^{6}$ En 1984, cobró estado público por primera vez, el caso de una persona que falleció de VIH-Sida en Chile. Ese mismo año, el régimen de Augusto Pinochet 0modificó el artículo 2 del decreto 362 sobre Enfermedades de Transmisión Sexual, incorporando "el síndrome de inmunodeficiencia adquirida (SIDA)". Con este acto, el Ministerio de Salud incorporaba el SIDA como enfermedad en el sistema de salud pública
} 


\section{Pasados suspendidos. Estrategias represivas y tecnologías biopolíticas sobre las disidencias sexo-genéricas durante la dictadura de Augusto Pinochet en Chile}

homosexuales organizadas públicamente, marcando así una historia de organización política relativamente tardía en relación con otros países de la región. Esta dilación o retraso de los activismos sexo-genéricos tiene efectos en lo que hemos podido configurar como archivo de las vidas LGBT en dictadura, al menos hasta ahora. Los registros activistas, militantes o testimoniales de ese periodo donde la comunidad LGBT haya elaborado su experiencia en sus propios términos son escasos y fragmentarios. También pueden considerarse algunos textos e imágenes producidos desde sectores minoritarios del mundo del arte antidictatorial de esos años ${ }^{7}$. Esto ha implicado, para los que hemos querido volver a sobre ese tiempo, sumergirnos en las huellas dejadas en la prensa sensacionalista o en el mucho más esquivo, árido y distante del archivo médico-legal.

En este texto intento visibilizar otras zonas, que no son las de los dos polos recién expuestos. No para negar o superar los extremos que las imágenes del arrasamiento o de una sexualidad no heternormativa habilitada por el mercado proyectan. Sino para pensar otros puntos de contacto con un pasado que han quedado en suspenso y que permitan complejizar el modo en que entendemos las tecnologías represivas y biopolíticas sobre la población LGBT, y que permitan interrogar las formas de periodización que han organizado los relatos de la historia reciente bajo la distinción dictadura/posdictadura en Chile.

\section{Hipótesis de trabajo}

La dictadura de Augusto Pinochet, tuvo como una de sus características distintivas, la articulación entre la aplicación sistemática de políticas de tortura, fusilamiento y desaparición de personas y la instauración simultánea (y no posterior) de políticas económicas que promovieron la apertura indiscriminada al comercio internacional, la reducción del gasto público y la liberalización financiera, convirtiendo a Chile en el primer laboratorio neoliberal del planeta (Garate, 2015) ${ }^{8}$. Los militares pusieron en práctica métodos de represión excepcionales e ilegales transgrediendo las formas de represión consentidas por el marco jurídico tradicional, con el fin de aniquilar a los grupos marcados como "opositores políticos" y amedrentar a la población (Bonasso, 1990).

Como señala el filósofo chileno Willly Thayer (2004) "el golpe no ocurrió en la

\footnotetext{
${ }^{7}$ El trabajo que los artistas chilenos Carlos Leppe y Juan Domingo Dávila realizaron desde mediados de la década de los setenta, la escritura de Nelly Richard, las acciones de las Yeguas del Apocalipsis, trabajos que combinaron fotografía y testimonio como La Manzana de Adán, fueron el territorio de las primeras enunciaciones politizadas de formas de sexualidad y de identificación de género que ponían en cuestión las normas cis-heterosexuales, y pueden ser consideradas antecedentes fundamentales para pensar las disidencias sexo genéricas en Chile en el período dictatorial. Ver: Richard, 1980, 1985, 1993.

${ }^{8}$ Es preciso señalar que la liberalización de la economía chilena no se hizo solo desde un ministerio de economía, sino también desde una Oficina central de Planificación (ODEPLAN), a cargo de una segunda generación de economistas formados en Chicago y de políticos ligados a la derecha política y al catolicismo integrista.
} 


\section{Fernanda Carvajal}

historia de Chile, le ocurrió a la historia de Chile" (p.20-21), inaugurando así un nuevo tiempo hegemónico. Para Thayer la dictadura no fue un paréntesis en la historia de Chile sino que, en su autodeclarado estado de excepción, confirmó los más de doscientos años de violencia política republicana en nombre de la ley. Al mismo tiempo, la dictadura perpetuó esa violencia como transición desde el Estado al mercado como principal regulador de la sociedad. En nombre del progreso, la superación o la modernización como norma histórica la dictadura civico-militar ejerció la gobernabilidad tanto de acuerdo al binomio represión / consentimiento (basado en el monopolio estatal de la violencia y en los instrumentos ideológicos de persuasión), como en base a una forma de gobierno neoliberal (que organiza los cálculos y los afectos de la maquinaria social a través del impulso de libertades, la producción de la desigualdad y el menoscabo de la recomposición de los lazos colectivos).

En este artículo, parto del supuesto de que este rasgo, tiene un correlato en la convivencia de distintas tecnologías de producción sexogenérica, donde un régimen disciplinario del sexo, va abriendo lugar, de modo parcial, fragmentario y contradictorio, a un modelo más flexible de modulación de la identidad y la sexualidad, de acuerdo a lo que Preciado ha llamado tecnologías farmacopornográficas (Preciado 2014) de producción de los cuerpos. ${ }^{9}$ Esto no implica, sin embargo, marcar la trayectoria en línea recta de una supuesta "modernización sexual", que implicaría dejar atrás los rasgos disciplinarios. Al contrario, me interesa observar la convivencia tensa, turbulenta y superpuesta de distintas tecnologías de regulación sexo-genérica.

No es difícil ver como la dictadura reforzó un régimen disciplinario del sexo al intensificar la propagación del modelo familiar heterosexual como principal matriz de identificación de lo masculino y lo femenino según valores católicoconservadores (Grau et al., 1997). La dictadura impuso un discurso militaristapatriarcal que exacerba las identificaciones viriles a la retórica de mando (Richard, 1993) y promovió la figura tradicional de maternidad, que ubicaba a las mujeres en el rol de guardianas morales de la sociedad y depositarias de las tradiciones nacionales (Junta Nacional de Gobierno, 1974). En este período, también estuvieron vigentes los artículos del Código Penal no 365 (que tipifica como delito la práctica de sodomía, específicamente homosexualidad masculina, desde el año 1875) y no 373 (de "el ultraje a las buenas costumbres" utilizado para penalizar el travestismo y la prostitución callejera). Es preciso aclarar que estos artículos se aplicaron antes,

\footnotetext{
${ }^{9}$ Retomo la distinción que hace Preciado entre un régimen disciplinario del sexo, basado en las técnicas de producción de identidades biológicas concebidas como verdades anatómicas a partir una lógica dicotómica (hombre/mujer) y que organizan la sexualidad en torno a la díada heterosexualidad/homosexualidad, y el régimen farmacopornográfico, según el cual, técnicas de control de los cuerpos no intentan castigar o corregir los desvíos de la norma desde el exterior, sino modular los cuerpos a partir de técnicas como el uso de materiales sintéticos, prótesis o el consumo de hormonas, que se infiltran en el interior el cuerpo individual y modifican el modo de concebir el cuerpo, para producir artificialmente una corporalidad estándar, pero de tal modo que cada órgano ya no corresponde "a una única función y aun único emplazamiento" (Preciado, 2014:154).
} 


\section{Pasados suspendidos. Estrategias represivas y tecnologías biopolíticas sobre las disidencias sexo-genéricas durante la dictadura de Augusto Pinochet en Chile}

durante y después del periodo dictatorial. Sin embargo, tal como sucede en otros países de la región bajo dictadura como Argentina ${ }^{10}$ y Brasil ${ }^{11}$, hasta el momento no hay registros de una política represiva ideada por los militares que tuviera como finalidad la persecución directa de la diversidad sexual por su condición de tal ${ }^{12}$.

Pero lo que busco enfatizar es que simultáneamente, es posible advertir desde los primeros años de la dictadura, indicios de la gradual emergencia de técnicas farmacopornográficas de control de los cuerpos que dan cuenta de mecánicas de poder más difusas, que se implican en la modulación del deseo subjetivo, la diversificación del mercado sexual y en la medicalización de la sexualidad. Desde fines de los años 1970s, el burdel tradicional y la prostitución de "asiladas" fueron reemplazados por servicios individuales y reservados que tenían lugar en topless, saunas y cabarets (Salazar \& Pinto, 1999); y a su vez, comienzan a surgir las primeras discotecas gay (Contardo, 2011), asociadas al fortalecimiento del mercado nocturno y sexual. Además, en lugar de enmarcar la vía médico-legal del cambio de sexo desde una lógica prohibitiva y que le diera un fuerte poder al Estado para decidir sobre el cuerpo de las personas trans (como sucedió por ejemplo en la dictadura argentina ${ }^{13}$ ) durante la dictadura chilena se abrió un espacio discreto ${ }^{14}$ para que las cirugías de "cambio de sexo" pudieran llevarse a cabo en hospitales públicos y clínicas privadas, llegando a ofrecerse como un servicio gratuito para beneficiarios del sistema público de salud en el Hospital van Buren de Valparaíso. Apelando a la ley 17.344 que autoriza el cambio de nombres y apellidos, mujeres trans ${ }^{15}$ que se sometieron a la cirugía, lograron en algunos casos y a condición del criterio del juez de turno, el cambio registral de nombre y sexo.

Los procesos medico-legales de "cambio de sexo" se formalizaron a través de la discreta admisibilidad de las cirugías y de la judicialización del cambio civil de

\footnotetext{
10 Para el caso argentino ver el texto de Insausti, J. (2015). Los cuatrocientos homosexuales desaparecidos: Memorias de la represión estatal a las sexualidades disidentes en Argentina. En D. D’Antonio (Ed.), Deseo y represión. Sexualidad, genero y estado en la historia reciente argentina. Buenos Aires: Ediciones Imago Mundi; Figari, Carlos (2010). "El movimiento LGBT en América Latina: institucionalizaciones oblicuas", en Movilizaciones, protestas e identidades políticas en la Argentina del bicentenario, compilado por Astor Massetti, Ernesto Villanueva y Marcelo Gómez. Buenos Aires: Nueva Trilce.

${ }^{11}$ Para el caso de Brasil ver: Green, J., \& Quinalha, R. ( 2015). Ditadura e homossexualidades: Repressão, resistência e a busca da verdade. São Carlos: Edufscar.

12 Una excepción en este sentido es la Dictadura de Alfredo Stroessner en Paraguay, donde sí es posible identificar una política represiva dirigida a la homosexualidad masculina: Carbone, Rocco (2016). Putos de fuga. Diversamente deseante en Paraguay. Los Polvorines: Universidad Nacional de General Sarmiento.

${ }^{13}$ Ver: Farji, A. (2017)La ley de los cuerpos. Análisis de dos decisiones judiciales en torno al "cambio de sexo" (Argentina, 1966-1974). Revista Mora, 23, 65-78.

http://dx.doi.org/10.34096\%2Fmora.n23.5199

${ }^{14}$ Es importante aclarar que, si bien los procedimientos médico-legales en torno al "cambio de sexo" no se dieron a espaldas de la institucionalidad dictatorial, los antecedentes reunidos hasta ahora, no permiten hablar de una política oficial en relación a las cirugías de modificación genital. Ver: (Carvajal, 2019)

${ }^{15}$ A lo largo de este articulo utilizo categorías contemporáneas como "mujer trans" o "feminidades trans", aunque estos términos no eran utilizados aún en el período estudiado.
} 


\section{Fernanda Carvajal}

nombre y sexo. Esto implicaba que una vez realizada la cirugía, quien solicitaba el cambio civil de sexo debía volver a someterse a un peritaje médico que daba lugar a procedimientos abusivos y de castigo físico y moral, que dejaban en evidencia como contracara de un marco legal permisivo, la vulnerabilidad de la población trans a la violencia institucional. Esta convivencia de permisividad y vulneración que trabaja en la judicialización del "cambio de sexo", parece hablar de las modalidades neoliberales del arte de gobernar que, en una sociedad que comienza a ser modelada según la multiplicidad y la diferencia, confronta y quita legitimidad a las intervenciones de tipo disciplinario y planificador del Estado, promoviendo en cambio, una proliferación del arbitraje jurídico que añade formas más sofisticadas de violencia sobre la población trans (Carvajal, 2019).

En ausencia de organizaciones LGBT (que, como señalé arriba, en Chile se conformaron recién a partir del año 1991 durante el período postdictatorial) fueron los miembros de la Sociedad Chilena de Sexología Antropológica (SChSA), junto a otros médicos y abogados, los que contribuyeron a abrir un campo de acciones médico-legales en torno al "cambio de sexo". En efecto el discurso sexológico de la década de 1960 es un antecedente fundamental para comprender como funcionó el "cambio de sexo" como dispositivo durante los primeros años de la dictadura. En el año 1967, los médicos de la Sociedad Chilena de Sexología Antropológica decidieron discutir la factibilidad de iniciar una vía médico-legal para el "cambio de sexo" en el país, como un modo de ofrecer una solución a la criminalización de las mujeres trans. En el libro Cambio de sexo: puntos de vista antropológico, biológico, embriológico, genético, clínico endocrinológico, psiquiátrico, religioso católico y jurídico: con un apéndice sobre correcciones quirúrgicas, los integrantes de a SChSA discuten un caso publicitado en la prensa, que relataba la detención de una camarera en su lugar de trabajo bajo la aplicación del artículo 373 del Código Penal, debido a que su documento no coincidía con su expresión de género. ${ }^{16}$ La anécdota, que es retomada en distintos textos de la SChSA, era un caso ejemplar porque ponía a la persona de "sexo indefinido" en una escena laboral (que resalta el aspecto moral de "ganarse la vida horadamente" como un modo de alejar trabajo sexual como "destino" de las personas trans):

con toda razón el detenido argumentó que su figura y sus maneras, que incluían timbre de voz que no había podido corregir, hacían que en ninguna parte le dieran trabajo cuando lo solicitaba vestido de hombre, por lo que si quería ganarse la vida honradamente tenía que hacerlo vestido de mujer. No sabemos que exista la posibilidad de que cuando médicos comprueban la imposibilidad de cambiar estos caracteres [se refiere a los caracteres sexuales secundarios], puedan dar a él o a la afectada, un certificado válido para que estos individuos no sean molestados por la policía (Quijada, 1968, p. 23).

\footnotetext{
${ }^{16}$ Esta discusión ha quedado registrada en el libro: Quijada, O., Parada, J., Barrera, R., Tellez, R., Godoy, M., Peró, J. y Gonzalez, M., 1968. Cambio de sexo: puntos de vista antropológico, biológico, embriológico, genético, clínico endocrinológico, psiquiátrico, religioso católico y jurídico: con un apéndice sobre correcciones quirúrgicas. Buenos Aires: Joaquín Almendros.
} 


\section{Pasados suspendidos. Estrategias represivas y tecnologías biopolíticas sobre las disidencias sexo-genéricas durante la dictadura de Augusto Pinochet en Chile}

Y más adelante agregan:

Recuérdese aquel individuo que debe emplearse como mujer, única posibilidad de ganarse la vida honradamente, pues vestido de hombre y pidiendo ocupaciones masculinas, no le dan trabajo en ninguna parte a pesar de sus genitales externos de varón. Irracionalmente llevado a prisión por poseer dichos genitales que no usa y de nada le sirven como si únicamente en ellos debiese descansar el derecho legal a determinadas vestimentas. No lo apoyan legal ni moralmente su voz, formas corporales o maneras, por congénitas e irrenunciables que sean que lo hacen ser reconocido de lejos como mujer o con mayor razón de cerca. Estas personas piden, ya como necesidad vital que se les prive de esos atributos físicos que son para ellos estigmas que les impide la única existencia normal que pueden llevar. En realidad lo transformado es solamente la apariencia externa de unos detalles orgánicos en individuos operados para hacerlos mujeres más completas pues eran ya muy poco o nada varoniles" (p.112).

Los integrantes de la SChSA presentaban la modificación genital como la solución que permitiría "definir" el sexo y otorgar así el ingreso a la ciudadanía. La posibilidad de definir a la persona en un sexo mediante la cirugía, articulaba así el poder médico, las tecnologías de normalización sexo-genérica, la desigualdad de clase, las dificultades de acceso al trabajo, la criminalización de las personas trans y la obsesión por el nudo entre la genitalidad y la verdad del sujeto. En este argumento, la cirugía de "cambio de sexo" era presentada desde un discurso humanitario, modernizador y desde una temporalidad ligada al progreso, como la forma de garantizar, el "derecho"17 e incluso el "deseo" de las personas de definirse en un sexo (Quijada, 1968). Este modo de justificar la cirugía persistió en el discurso médico de este período, tanto textos escritos años más tarde por el médico Osvaldo Quijada ${ }^{18}$, como en escritos del urólogo Guillermo Mac Millan que haciendo referencia a la aplicación del artículo 373 del código penal, señala que tras la operación, la persona solicitante ahora "rehabilitada (...) termina su conflicto con la ley por su conducta juzgada como inmoral o deshonesta" (Mac Millan, 1988, p. 95).

La construcción de la cirugía de modificación genital como frontera entre la legalidad e ilegalidad de una identidad, es lo que me permite pensar el dispositivo del "cambio de sexo" como estrechamente entramado a las formas de criminalización de las disidencias sexo-genéricas, como el artículo 373 del código penal.

Ahora bien, cuando me refiero al "cambio de sexo" como dispositivo, no estoy pensando en un concepto dado (no es un a priori teórico) si no en una categoría que fue siendo construida a partir del archivo disponible, a través de un análisis

\footnotetext{
${ }^{17}$ Lo integrantes de la Sociedad Chilena de Sexología inscribían este discurso garantista en lo que en esos años en Chile se denominaba "derecho a la personalidad" (González Berendique, 1968).

18 Por ejemplo, en un texto de 1980, donde retoma el caso de la camarera y señala: "cuando son descubiertos resulta paradójico que la policía los detenga por infringir las buenas costumbres no haciéndolo cuando vestidos varonilmente ridiculizan la masculinidad y ridiculizan la feminidad" (Quijada, 1980, p. 2)
} 


\section{Fernanda Carvajal}

relacional entre distintos discursos médicos, jurídicos y periodísticos, que dejaron huella en una serie de documentos a partir de fines de los años sesenta en Chile. En efecto, el "cambio de sexo" funciona en los documentos analizados como un enunciado opaco, contradictorio, pseudo-científico, que va adquiriendo significados móviles y heterogéneos pero que al mismo tiempo tiene efectos sobre los cuerpos. Así, una de las contradicciones que operaron en el "cambio de sexo" como dispositivo, fue que, al contrario de lo que planteaba el discurso médico, la ubicación de las personas trans en una posición de infracción a la ley continuó, en especial porque en Chile (en los años setenta y hasta el año 2012), era posible someterse a una cirugía de modificación genital, pero el cambio civil de sexo y nombre en los documentos de identificación no estaban asegurados por la ley, lo que dejaba a las personas trans expuestas a diferentes formas de violencia represiva e institucional (Rivera 2009) ${ }^{19}$. Como ha mostrado Garrido (2016), homosexuales, travestis y mujeres trans que ejercieron el trabajo sexual en los años 70s y 80s se vieron expuestas a episodios de violencia física y sexual por parte de la policía y fueron detenidas tanto por ofensa a la moral y las buenas costumbres como por vagancia.

\section{La continuidad de las políticas represivas sobre las disidencias sexogenéricas}

En su investigación sobre deseo homoerótico, Gonzalo Salazar (2015) ha mostrado cómo durante el período previo a la dictadura, entre 1950 y 1973, las sexualidades disidentes lograron abrirse camino en pequeños espacios de libertad ligados a la bohemia, el hampa y los mercados del sexo en un contexto que las relegaba al destierro cultural, a la represión y prevención sanitaria de parte del Estado.

Durante el período del denominado "Estado Asistencial Sanitario" (1938-1973) (Illanes, 2010), el Servicio Nacional de Salud y la Brigada de Delitos Sexuales fueron los dos principales organismos estatales de disciplinamiento y normalización sexual. Se trataba de una matriz biopolítica que entendía las disidencias sexogenéricas, las prácticas ligadas a la homosexualidad, el lesbianismo el travestismo, el trabajo sexual, como problemas de salud moral y social de la población, es decir, como "desviaciones sociales" (antes que, por ejemplo, como "enfermedades mentales"). Como señala un reportaje publicado en abril del año 1973 en la revista VEA: "el problema de la homosexualidad se aborda en Chile desde dos ángulos prácticos: represión y prevención sanitaria. Se protegen así las buenas costumbres, la moral y se evita que la prostitución de invertidos produzca focos de enfermedades venéreas" («El sórdido submundo...»1973, p.6).

Durante el período previo a la dictadura el Servicio Nacional de Salud tuvo a su cargo los controles de enfermedades venéreas como una forma de regulación y construcción social de las "sexualidades peligrosas" (Castejón, 2004). Esta política buscaba llevar un registro tanto de la prostitución (femenina y masculina) como de

${ }^{19}$ Como ha señalado Andrés Rivera, estos procedimientos abusivos dieron lugar a que algunos jueces cambiaran el nombre pero no el sexo de los documentos de identificación, exponiendo a las mujeres transexuales a una serie de problemas y restricciones (Rivera, 2009) 


\section{Pasados suspendidos. Estrategias represivas y tecnologías biopolíticas sobre las disidencias sexo-genéricas durante la dictadura de Augusto Pinochet en Chile}

la homosexualidad. Así, desde el año 1965, se produjeron estadísticas para identificar y llevar una contabilidad de individuos "homosexuales"20.

El foco del acoso policial estuvo dirigido hacia el "ejercicio de la prostitución homosexual callejera" o "ambulatoria" o a los "homosexuales que se esconden en alguna actividad" (el término travesti no es utilizado en el reportaje citado). La principal vía de criminalización era la aplicación del artículo 373 que penaliza las ofensas al pudor y las buenas costumbres. A su vez, la policía perseguía a personas codificadas como sospechosas que circulan por cines porno o que "merodean colegios", sancionándolos por delitos como la "corrupción de menores" o las "proposiciones deshonestas". Ahí se incluía también a mujeres lesbianas que "acosaban" menores de edad en el ámbito escolar ${ }^{21}$. Una nota anterior, publicada en la revista VEA en el año 1970, señalaba que la Policía de Investigaciones tenía más de quinientas fichas de homosexuales (Correa, 1970). La nota no especificaba cuál era el delito de los varones homosexuales fichados, más bien daba por sentado que la orientación sexual era razón suficiente para abrir un prontuario (Contardo, 2011, p. 276)

¿Qué sucedió más adelante, durante el período dictatorial? Es preciso recordar que a partir del Golpe de Estado cambió radicalmente las formas de habitar y circular por la ciudad. El control del espacio público se dio a través de la consecutiva declaración de estados de excepción, toques de queda y estados de sitio $^{22}$. Por un lado, las notas relevadas en la prensa sensacionalista durante los primeros años de la dictadura (entre 1974-1977) dan cuenta de la continuidad de las formas del acoso policial sobre las disidencias sexo-genéricas. Permiten verificar que muchas de las detenciones narradas, ocurrían en medio de lo que parecen ser habituales rondas y redadas efectuadas momentos previos al toque de queda, asumidas "con firmeza" (“Guerra a muerte a los homosexuales en Viña", 1977) tanto por la policía civil como por la policía uniformada. La figura delictual rigurosamente aplicada, era el artículo 373 que penaliza los escándalos contra la moral y las buenas costumbres. En ocasiones se añadía la figura de vagancia o tenencia de drogas. Las notas también dejan ver que la policía continuaba usando el sistema de fichaje de homosexuales y

\footnotetext{
20 El médico del Servicio Nacional de Salud entrevistado en la nota, señala que considerando "homosexuales asilados y ambulatorios (...) las cifras sobre esta población santiaguina es variable podría decir que estadísticamente barajamos una cantidad de 150 a 290". Señala que los controles se realizan cada veintiún días para detectar enfermedades como sífilis y gonorrea aunque "actualmente ninguno está enfermo" («El sórdido submundo....»1973, p. 7)

${ }^{21}$ La Brigada de Delitos Sexuales, entonces, (...) fue creada para combatir toda clase de desviaciones. Su misión: proteger a las gentes de la acción de anormales (...).El homosexual adulto que practica su anormalidad en privado o en forma oculta, no nos interesa (...) lo realmente grave y que reprimimos con toda energía es el homosexual que atenta contra las buenas costumbres y la moral («El sórdido submundo...»1973, p. 6).

${ }^{22}$ Como se señala en el El Informe de la Comisión Nacional sobre Prisión Política y Tortura, "Los estados de excepción serían renovados sin interrupciones durante quince años seguidos, mientras el estado de sitio - categoría que ampliaba aún más la discrecionalidad del poder en su tarea represiva, concediéndole a las autoridades de gobierno la facultad de ordenar arrestos arbitrarios, censurar la prensa y suspender un cúmulo de libertades civiles- se prolongaría hasta marzo de 1978, y posteriormente se restableció en dos ocasiones, ambas en la década de 1980" (2005, p.172)
} 


\section{Fernanda Carvajal}

tarjetas de control por vagancia, y que el traslado a los tribunales, obligaba a quienes podían haber sido (no lo sabemos) locas, travestis o mujeres trans, a ponerse vestimentas masculinas. Así, quienes protagonizan estos relatos eran expuestos a una doble violencia, a la arbitrariedad de la detención y a formas de negación sobre sus formas de identificación y nombres femeninos, inmediatamente "rectificados" por los nombres masculinos de nacimiento. Los procedimientos de detención quedan bien registrados en la siguiente nota que narra el supuesto equívoco de un grupo de "raros" intentando "seducir" a agentes de la policía vestidos de civil:

Los raros lucían pelucas rubias y recargado maquillaje en sus rostros, incluyendo pestañas postizas (...) Con coquetos ademanes habían conquistado ya a dos varones trasnochadores, y buscaban un tercero cuando se toparon con miembros de la comisión civil de la segunda comisaría central. Los interceptaron en la vía publica y previos guiños insistentes los invitaron a sumarse al grupo. Solo entonces se percataron de que eran policías. Los raros fueron invitados al cuartel de Avenida Argentina para cumplir una corta detención en esa unidad policial. Esta mañana pasaron a disposición del tribunal de policía local, por infracción al a moral y las buenas costumbres. Fue preciso conseguirles vestimentas varoniles para trasladarlos a tribunales ("Raros querían conquistar a un policía”, 1977, p.5) 23

Antes que un plan sistemático sobre las personas LGBT por su condición de tales, la revisión de la prensa del periodo 1974-1977, que coincide con los años más represivos de la dictadura chilena, permite verificar la continuidad de una política represiva ejecutada por las fuerzas de seguridad vigente antes y durante la dictadura: verificable en las fichas de homosexuales y la aplicación del código 373 del código penal. A diferencia de los edictos policiales o los códigos contravencionales argentinos que tienen un estatuto jurídico más débil y discontinuo pues operan a nivel provincial, en Chile el artículo 373 (así como 365 que penalizaba la sodomía entre varones) está incrustado en el código penal, reforzando el modo en que se nos aparecen como atemporales y constitutivos al Estado Nación. En particular el artículo 373 es un tipo penal abierto que exhibe la legalidad como excepción, en tanto lleva a una aplicación arbitraria y prácticas abusivas por parte de las fuerzas policiales y de seguridad pública, que lo utilizan para llevar adelante "detenciones fundadas en la estigmatización y discriminación" (Senado, Congreso Nacional de Chile 2006).

Una de las preguntas que atraviesa esté artículo es si debemos separar el análisis de

\footnotetext{
${ }^{23}$ Por ejemplo: "Carlos Alarcón Toro, apodado la Vicky o la Piba de 21 años de edad, recientemente llegado de argentina, jugaba al pillarse con lo raros Alejandro Mora Mora de 45 años, la Aleja, y Robinson Cueto Duran, la Polla, de 26 años de edad" ("iTodos presos! Homosexuales danzaban desnudos en la noche en playa caleta abarca.", 1977) o "Luciendo minifaldas, pelucas y maquillaje facial, fueron trasladados hasta el Cuartel de avenida Argentina, Lautaro Canilao Collio, la "Pascuala", de 19 años, Adonis Uribe Matus, de 25 años, la "Madona" y Jorge Alegría Droguett de 25 años, la "Miguelina" ("Tres raros detenidos en el barrio chino", 1977).
} 


\section{Pasados suspendidos. Estrategias represivas y tecnologías biopolíticas sobre las disidencias sexo-genéricas durante la dictadura de Augusto Pinochet en Chile}

las políticas represivas de larga duración dirigidas a aquellos sujetos indeseados de la nación y distinguirlas de aquellas acotadas al periodo dictatorial, que tuvieron como objetivo perseguir a las izquierdas y disidencias político-ideológicas como plan sistemático ejecutado por las Fuerzas Armadas. 0 en cambio, si nuestra tarea es visibilizar "los enlaces entre los aspectos legales e ilegales, y entre las prácticas excepcionales de la represión clandestina y las dinámicas institucionales y burocráticas regulares preexistentes" (D'Antonio, 2015, p. 11). Es importante tener en cuenta que históricamente la policía chilena ha tenido una tendencia a la militarización y que en 1974 la Junta Militar decretó que tanto la policía uniformada como la civil fueron asimiladas por las Fuerzas Armadas pasando a depender del Ministerio de Defensa (Maldonado Prieto, 1996), lo que hace posible preguntarse en qué puntos las fronteras entre diferentes formas y tiempos de la represión al interior del Estado, se habrían vuelto porosas, en qué momentos o en qué modalidades, pudieron haber producido efectos de intensificación mutua.

Como han mostrado distintos autores (Acevedo \& Elgueta, 2009; Contardo, 2011) el contexto de la Unidad Popular, marcado por una fuerte homofobia, se erigía sobre la construcción de una masculinidad fuerte, basada en la fuerza física y la producción, encarnada en el minero, el obrero industrial, el trabajador de la construcción. La acusación de ser homosexual fue un enunciado utilizado por la prensa sensacionalista afín al gobierno de Allende para deslegitimar el discurso del adversario político. En ese mismo período, la homosexualidad y el travestismo aparecían en la prensa recurrentemente adheridos a crímenes pasionales, construidos como series de asesinatos, violaciones o abusos ${ }^{24}$.

En contraste, lo que las notas relevadas en los primeros años de la dictadura están transcribiendo son prácticas de una sexualidad pública. Transcribo aquí algunos de los titulares: "Bailando flamenco cae homosexual drogadicto", "iTodos presos! Homosexuales danzaban desnudos en la noche en playa Caleta Abarca.", "Raros querían conquistar a un policía", "Raros y lanzas detenidos en redada de medianoche", 1977; "Tres raros detenidos en el barrio chino".

Estas notas no hablan solo de "fiestas negras", o del incipiente mercado nocturno gay que comenzó a consolidarse a fines de los setenta. Transcriben relatos de cerros y playas tomadas por grupos de homosexuales para practicar sexo público. Lanzan imágenes de otras posibilidades sexoafectivas, incluso aunque estén acechadas por la amenaza. Así, por ejemplo, el 26 de enero de 1977 en el diario La Estrella de Valparaíso publica "iTodos presos! Homosexuales danzaban desnudos en la noche en playa Caleta Abarca", que relata:

\footnotetext{
${ }^{24}$ La relación entre homosexualidad y muerte en la prensa durante el periodo de la Unidad Popular ha sido trabajado por diferentes autores (Acevedo \& Elgueta, 2009; Contardo, 2011). Transcribo aquí algunos titulares analizados por Oscar Contardo en el capítulo 6 de su libro Raro, una historia gay de Chile: "Feroz asesinato entre maracos. Se trata de gente jai que ama el Arrayan" Puro Chile, 27 de abril de 1971 o "Detective mató a loca de hot-pants" Puro Chile, 5 de octubre de 1971; "Balearon a maricón del piano: Carmen 664" Puro Chile, 30 de marzo de 1971.
} 


\section{Fernanda Carvajal}

Con traje de adanes, pero sin la hoja de parra, fueron sorprendidos en la playa caleta abarca tres homosexuales a la luz de la luna (...). Aun cuando a las 22:30 horas esos parajes costeros estaban solitarios, igual faltaban a la moral y las buenas costumbres. Los funcionarios de la brigada de narcóticos y drogas peligrosas que efectuaban una ronda en busca de mariguaneros se toparon con los homosexuales quienes participaban de un recreo nocturno en compañía de otros individuos que huyeron al percatarse de la presencia de la policía en la playa. Para ser remitidos al cuartel policial (...) debieron colocarse diminutos trajes de baño. Posteriormente fueron enviados al tribunal de turno en calidad de vagos (“iTodos presos! Homosexuales danzaban desnudos en la noche en playa caleta abarca", 1977).

La página del diario publica la noticia del trío de "homosexuales" que hacía nudismo nocturno en la caleta de pescadores junto a un breve artículo que señala que, en el mismo lugar, había sido encontrado recientemente dos cadáveres masculinos expulsados por el mar. El choque entre la imagen de liberación en el acto de nudismo público de tres homosexuales y la borradura de las huellas de un crimen en el cadáver arrojado por el mar, que podría remitir a la desaparición forzada en tiempos de dictadura, produce una suerte de suspensión o detención temporal. Permite pensar en diferentes regímenes y estratos temporales que atraviesan un mismo momento histórico, asincronías, diferimientos, que impide relatar estos episodios en una trayectoria lineal.

Al mismo tiempo quisiera notar que estas breves notas de prensa permiten pensar que prácticas homosexuales anónimas que transcurrían en diferentes espacios clandestinos o semipúblicos como saunas o cines porno, abandonan los subsuelos para ocupar la superficie de la ciudad, más precisamente la ciudad sitiada ${ }^{25}$. Como una suerte de posibilidad distópica de un tiempo-espacio que se abre cuando la ciudad se va vaciando ante la proximidad del toque de queda, lo suficientemente peligroso y depurado de heterosexualidad como para habitarlo como un transitorio "paraíso perverso" (parafraseando a Perlongher). Una nota publicada el 17 de enero de 1977 bajo el titulo "Guerra a muerte a los homosexuales en Viña", alertaba sobre a la aparición de "homosexuales e individuos amorales" en diversos sectores de la ciudad de Viña del mar:

Se han quejado de la aparición de homosexuales en los prados que corren en forma paralela a la ribera norte del estero marga-marga. Estos individuos llegan en parejas hasta ese lugar cuando comienza el atardecer y sus desviados instintos les hacen realizar una serie de actos reñidos por completo con la moral y las buenas costumbres (...) Recientemente la comisión civil de la prefectura de carabineros (...) sorprendió a las 22 horas (...) a dos homosexuales que se hacían el amor a vista y paciencia de los

\footnotetext{
${ }^{25}$ En el libro Sida en Chile. Historias Fragmentadas de Amelia Donoso y Víctor Hugo Robles, se reúnen algunos relatos de vida de activistas que permiten reconstruir algunos de los circuito de gire homosexual de los años dictatoriales (A. Donoso \& Robles, 2015).
} 


\section{Pasados suspendidos. Estrategias represivas y tecnologías biopolíticas sobre las disidencias sexo-genéricas durante la dictadura de Augusto Pinochet en Chile}

transeúntes ("Guerra a muerte a los homosexuales en Viña", 1977, p.3).

Estos fragmentos dan cuenta del uso efímero de zonas de la ciudad delimitadas y "accionadas por el deseo homoerótico" (Salazar 2015, p. 73) -para usar la expresión de Salazar-. Se trataba de lugares y recorridos re-configurados por el uso deseante que las disidencias sexo-genéricas hicieron de espacios que no estaban concebidos para esos fines. En efecto las notas de prensa operan la restitución de la codificación y ordenamiento de la ciudad sitiada, invocando no sólo al control policial si no también al "control ciudadano", llamando a la "responsabilidad a los vecinos quieres deben denunciar cualquier acto sospechoso de inmediato a la policía" ("Guerra a muerte a los homosexuales en Viña", 1977, p.3)

Mi propósito es pensar cómo estas breves notas de prensa permiten abrir otras zonas del pasado que se desenganchan tanto de las imágenes de la aniquilación como de las de una libertad sexual y de circulación habilitada por el mercado. El archivo no solo sirve como prueba de las preguntas que le hacemos, sino que también habla de un conjunto de procedimientos políticos y fuerzas institucionales que lo ponen a nuestra disposición (Snorton en Bychowsky et al., 2018). En el caso de la prensa sensacionalista esos procedimientos y fuerzas tienen que ver con la espectacularización, la patologización, la criminalización. No es posible pasar por alto, el efecto productivo y ejemplarizante que pueden llegar a tener la inscripción de la reiteración del castigo sobre esas formas de sexualidad no-normativa (que siguen incluso aquí acechadas por la muerte, como muestra el cadáver encontrado en Caleta Abarca). Pero es tal vez por esa misma razón, como ha señalado Snorton, que podemos considerar un compromiso ético, el acto de imaginar lo contrario de la evidencia documental en aquellos discursos que se han organizado para disminuir y desacreditar ciertos tipos de vidas. Esto no implica absorber las diferencias que produce la distancia histórica. Como han planteado los investigadores de las temporalidades trans (Bychowsky et al., 2018; Devun \& Tortorici, 2018) la especulación, la conjetura abierta, incluso el afecto pueden ser buenas guías a través de los archivos, especialmente cuando las figuras que buscamos parecen estar escritas fuera del tiempo. Se trata de poder conjugar esas guías con el cuidado que implica, al mismo tiempo, mantener la diferencia y la opacidad a la que nos confronta la distancia histórica, para no imponer las imágenes y contenidos de nuestro presente como una horma para el pasado. Quisiera cerrar este apartado, dejando abierta la pregunta, sobre si estos relatos, pedazos de vida capturados como mercancías informativas, pueden estar hablando también de tácticas y maniobras que dejaron huella de la persistencia, episódica y fugaz, de una "cultura de posibilidad sexual" (Crimp, 2005; Muñoz, 2009), incluso bajo dictadura.

\section{Conclusiones}

El corpus de notas revisadas, dejan huella de la vigencia de la aplicación del artículo 373, el fichaje de homosexuales, los abusos policiales contra la población LGBT, y dan cuenta de procedimientos atravesados por aspectos legales e ilegales, por dinámicas institucionales habitadas por políticas de excepción, que han sido 


\section{Fernanda Carvajal}

procuradas históricamente por distintas fuerzas de seguridad del Estado, desordenando el límite seguro y aliviante entre el antes, el durante y el después de la dictadura, mostrando los retornos de un tiempo represivo que no pasa, que no termina de pasar. Se trata de la continuidad de formas de excepcionalidad que podríamos calificar como de baja intensidad, por el modo discreto, permanente y focalizado sobre ciertos sectores de la población en que se ejecutan.

Por otra parte, considerar en serie las distintas notas de prensa que registraban detención de personas homosexuales o de género disconforme por la policía durante los primeros años de dictadura, permite leerlas no solo como el reverso represivo de las tecnologías biopolíticas en relación con la transexualidad que tuvieron lugar en esos años. Siguiendo la metodología de los estudios queer y trans la propuesta fue leer estos episodios también a partir de las prácticas de sexualidad pública que registran (oferta de sexo en la calle, nudismo, sexo en público). En un país que no vio surgir movimientos de liberación homosexual previos a la expansión del VIH-sida, esos relatos pueden ser leídos como huellas de otro tiempo queriendo emerger a fragmentos. No solo hablan de formas de sanción que no cesaron, a diferencia de lo que sugería Perlongher con la imagen de paraíso de libertad donde la policía pasa de largo y mira hacia un costado. Pueden ser considerados como episodios que exceden y descontrolan la razón punitiva: imágenes que a pesar de su suspensión (legal, histórica) dan cuenta de una "cultura de posibilidad sexual" que está fuera del tiempo y del espacio en más de un sentido: fuera del tiempo normativo familiarista, patriarcal y cis-heterosexual controlado por la dictadura. Fuera de la temporalidad de la derrota política que implicó la dictadura para una cultura y política de izquierdas igualmente cisheterocentrada. Pero también hablan de la imposibilidad y el destiempo al que se ven expuestos ciertos contextos, en los que la irrupción de movimientos queer y LGBT no calza, no logra sincronizarse con las cronologías euro-norteamericanas. Son huellas del exceso de una sexualidad pública y colectiva que incluso el presente de la normalidad neoliberal, formalmente democrática y post-vih, queda arrojada a un fuera de tiempo. Son huellas de vidas que han sido suspendidas, en el sentido de la sanción burocrática, que han sido inhabilitadas, tachadas y por eso también penden; están, en algún sentido, todavía pendientes como posibilidad futura.

\section{Bibliografía}

Acevedo, C., \& Elgueta, E. (2009). El discurso homofóbico durante la prensa popular izquierdista durante la Unidad Popular. Revista Izquierdas, 2(3), 1-12.

Baltra, L. (2012). La prensa chilena en la encrucijada. Ente la voz monocorde y la revolución digital. Santiago de Chile: LOM.

Betancur, O. del P. L. (2005). Amarilla y roja: Estéticas de la prensa sensacionalista. 
Pasados suspendidos. Estrategias represivas y tecnologías biopolíticas sobre las disidencias sexo-genéricas durante la dictadura de Augusto Pinochet en Chile

Universidad Eafit.

Bonasso, M. (1990). Terrorismo de Estado. Navarra, España: Txalaparta.

Bychowsky, M. W., Chiang, H., Halberstam, J., Lau, J., Long, K., Ochoa, M., ... Devun, L. (2018). "Trans*historicities" A Roundtable Discussion. TSQ: Transgender Studies Quarterly, 5(4), 658-685. https://doi.org/10.1215/23289252-7090129

Carbone, R. (2016). Putos de fuga. Diversamente deseante en Paraguay. Los Polvorines: Universidad Nacional Sarmiento.

Carbone, R., \& Soto, C. (2015). Memorias del subsuelo. "Es lo que se dice puto, así te voy a decir yo" Entrevista a Victoriano Silva por Clyde Soto y Rocco Carbone. Revista Sures, 5, 187-191.

Carvajal, F. (2019). Permisividad y vulneración. La judicialización del "cambio de sexo" durante la dictadura cívico-militar en Chile. Clepsidra. Revista Interdisciplinaria de Estudios Sobre Memoria., 6(12).

Castejón, R. (2004). Las enfermedades venéreas y la regulación de la sexualidad en la España contemporánea. Asclepio, LVI(2), 223-241.

Contardo, Ó. (2011). Raro. Una historia gay de Chile. Santiago de Chile: Planeta.

Correa, R. (1970, enero 8). Nidales de perversion de menores. Revista VEA, (1397), 7-8.

Crimp, D. (2005). Duelo y Militancia. En Posiciones críticas (pp. 99-115). Madrid: Akal.

D’Antonio, D. (2015). Introducción. En D. D'Antonio (Ed.), Deseo y represión. Sexualidad, género y Estado en la historia argentina reciente. (pp. 9-16). Buenos Aires: Imago Mundi.

Devun, L., \& Tortorici, Z. (2018). Trans, Time, and History. TSQ: Transgender Studies Quarterly, 5(4), 518-539. https://doi.org/DOI 10.1215/23289252-7090003

Donoso, A., \& Robles, V. H. (2015). Sida en Chile. Historias Fragmentadas. Santiago de Chile: Fundación Savia.

Donoso, C., \& Errázuriz, P. (1990). La Manzana de Adán. Santiago de Chile: Zona.

El sórdido submundo de los homosexuales. Los hombres que quieren ser mujeres. (1973, mayo 26). Revista VEA, (1765), 6 y 7.

Farji, A. (2017). La ley de los cuerpos. Análisis de dos decisiones judiciales en torno 


\section{Fernanda Carvajal}

al "cambio de sexo" (Argentina, 1966-1974). Revista Mora, 23, 65-78. http://dx.doi.org/10.34096\%2Fmora.n23.5199

Figari, C. (2010). El movimiento LGBT en América Latina: Institucionalizaciones oblicuas. En A. Massetti, E. Villanueva, \& M. Gomez (Eds.), Movilizaciones, protestas e identidades políticas en la Argentina del bicentenario. Buenos Aires: Nueva Trilce.

Foucault, M. (2006). La vida de los hombres infames. En La vida de los hombres infames (pp. 121-137). Buenos Aires: Caronte.

Frente de Liberación Homosexual. (1974). Declaración del Frente de Liberación homosexual de la Argentina. Masacran homosexuales en Chile. Somos, 2, 1-3.

Garate, M. (2015). La revolución capitalista de Chile (1973-2003). Santiago de Chile: Editorial Univerisdad Alberto Hurtado.

Garrido, J. C. (2016). Historias de un pasado cercano. Memoria colectiva, discursos y violencia homo-lesbotransfóbica en la dictadura militar y transición democrática en Chile. DOCUMENTO DE TRABAJO ICSO - N² 24 / Serie Jóvenes Investigadores.

González Berendique, M. A. (1968). Justificación jurídica. En Cambio de sexo: Puntos de vista antropológico, biológico, embriológico, genético, clínico endocrinológico, psiquiátrico, religioso católico y jurídico: Con un apéndice sobre correcciones quirúrgicas. (pp. 89-97). Buenos Aires: Joaquín Almendros.

Green, J., \& Quinalha, R. (2015). Ditadura e homossexualidades: Repressão, resistência e a busca da verdade. São Carlos: Edufscar.

Guerra a muerte a los homosxuales en Viña. (1977, enero 17). La Estrella de Valparaíso, p. 3.

Illanes, M. A. (2010). En el nombre del Pueblo, del Estado y de la Ciencia. Historia Social de la salud Pública en Chile 1880-1973 (Hacia una historia social del siglo XX). Santiago de Chile: Ministerio de Salud de Chile.

Lemebel, P. (1993, abril). La insoportable levedad del gay. Pagina Abierta, (84), 1819.

Mac Millan, G. (1988). El urólogo y el transexualismo. Revista Chilena de Urología, 51, 94-95.

Maldonado Prieto, C. (1996). Militarización de la policía: Una tendencia histórica chilena. En P. Waldmann (Ed.), Justicia en la calle. Ensayos sobre la policía en América Latina (pp. 7-73). Buenos Aires: Konrad Adenauer Stiftung, CIEDLA, ISLA.

Muñoz, J. E. (2009). Ghosts of Public Sex: Utopian Longings, Queer Memories. En 


\section{Pasados suspendidos. Estrategias represivas y tecnologías biopolíticas sobre las disidencias sexo-genéricas durante la dictadura de Augusto Pinochet en Chile}

Cruising Utopia: The Then and There of Queer Futurity (pp. 33-48). New York: New York University Press.

Perlongher, N. (2006). Informe sobre Chile. En Un barroco de trinchera. (pp. 87-93). Buenos Aires: Mansalva.

Quijada, O. (1968). El cambio de sexo y su justificación antropológica. En Cambio de sexo: Puntos de vista antropológico, biológico, embriológico, genético, clínico endocrinológico, psiquiátrico, religioso católico y jurídico: Con un apéndice sobre correcciones quirúrgicas. (pp. 17-31). Buenos Aires: Joaquín Almendros.

Quijada, 0. (1980, mayo 14). Contesta nota 05113 sobre rectificación de partidas en cambio de sexo. A Juan Bennett Urrutia Director general del Registro Civil $e$ Identificación. Recuperado de Archivo Guillermo Mac Millan.

Raros querían conquistar a un policía. (1977, marzo 12). La Estrella de Valparaíso, p. 5.

Richard, N. (1980). Cuerpo Correccional. Santiago de Chile: Francisco Zegers Editor.

Richard, N. (1985). La cita amorosa. Santiago de Chile: Francisco Zegers Editor.

Richard, N. (1993). Masculino/Femenino. Políticas de la diferencia y cultura democrática. Santiago de Chile: Francisco Zegers Editor.

Rivera, A. (2009). Informe sobre Chile -Violación a los DDHH de Personas Transexuales Quinta Ronda del Examen Periódico Universal ONU (Organización de las Naciones Unidas). Biblioteca Digital INDH.

Robles, V. H. (2009). Bandera Hueca. Historia del Movimiento Homosexual de Chile. Santiago de Chile: Arcis-Cuarto Propio.

Salas, F. (1989, mayo 1). Las Yeguas del Apocalipsis. Revista Cauce, (204), 26-29.

Salazar, G. (2015). El Deseo Invisible: Homoerotismo Masculino en Santiago de Chile (1950-1973). Universidad de Chile, Facultad de Filosofía y Humanidades, Santaigo de Chile.

Senado, Congreso Nacional de Chile. (2006). Modifica disposiciones sobre prostitución (No Boletín 4715 11). Recuperado de Senado website: http://www.senado.cl/appsenado/index.php?mo=tramitacion\&ac=getDocto\&iddo cto $=5101 \&$ tipodoc $=$ mensaje_mocion.

Snorton, R. (2019). Negra por los cuatro cosados. Una historia racial de la identidad trans. Barcelona: Edicions bellaterra. 


\section{Fernanda Carvajal}

Thayer, W. (2004). El golpe como consumación de la vanguardia (fragmentos). Pensamiento de los Confines, (15), 9-15.

¡Todos presos! Homosexuales danzaban desnudos en la noche en playa caleta abarca. (1977, enero 26). La Estrella de Valparaíso, 7.

Tres raros detenidos en el barrio chino. (1977, marzo 18). La Estrella de Valparaíso, p. 7.

Recibido: $13 / 09 / 2019$

Evaluado: $10 / 10 / 2019$

Versión Final: 30/11/2019 